\title{
Penentuan Dosen Teladan Berdasarkan Penilaian Kinerja Menggunakan Metode Simple Additive Weighting (Studi Kasus Dosen Unsulbar)
}

\author{
Kurniawati $^{1}$, Irfan $\mathrm{AP}^{2}$, Heliawati Hamrul ${ }^{3}$ \\ 1,2,3 Teknik Informatika, Teknik, Universitas Sulawesi Barat \\ ․ㅡurniawati.tid@gmail.com*, ${ }^{2}$ irfan ap@unsulbar.ac.id,
}

\begin{abstract}
The main objective in this study is to determine the Lecturer Performance Appraisal so that it is easy to find out which lecturers have good performance or can be called exemplary lecturers, using the Simple Additive Weighting method where the concept used is the weighted sum of the performance ratings of each alternative on all attributes. With the output in the form of information that is visualized by knowing the predicate of a lecturer who has a good performance or commonly called a model lecturer. Where lecturers who have a higher value predicate or are also called exemplary lecturers of West Sulawesi University, Informatics Engineering. The research method used refers to the Waterfal system development method for the software manufacturing process and the stages in the $S A W$ method for the results analysis process
\end{abstract}

Keywords:Decision Support System, Model Lecturer, Simple Additive Weighting (SAW).

\begin{abstract}
Abstrak
Tujuan utama dalam penelitian ini untuk mengetahui Penilaian Kinerja Dosen agar dapat dengan mudah mengetahui dosen yang memiliki kinerja baik atau bisa disebut dosen teladan, dengan menggunakan metode Simple Additive Weighting dimana konsep yang digunakan adalah penjumlahan terbobot dari rating kinerja dari setiap alternatif pada semua atribut dengan output berupa informasi yang divisualisaikan dengan mengetahui predikat dosen yang memiliki kinerja baik atau biasa disebut Dosen Teladan dimana dosen yang memiliki predikat nilai yang lebih tinggi atau disebut juga dosen teladan Universitas Sulawesi Barat. Metode penelitian yang digunakan mengacu pada metode pengembangan sistem Waterfal pada proses pembuatan perangkat lunak nya dan tahapan dalam metode SAW pada proses analisis hasil.
\end{abstract}

Kata kunci:Sistem Pendukung Keputusan, Dosen Teladan, Simple Additive Weighting (SAW). 


\section{Pendahuluan}

Universitas Sulawesi Barat memperoleh izin operasional melalui Keputusan Menteri Pendidikan dan Kebudayaan Nomor:229/D/0/2007 tanggal 31 November 2007 yang dikelola oleh Yayasan Pendidikan Indonesia Sulawesi Barat di bawah koordinasi Kopertis Wilayah IX Sulawesi. Tanggal 13 Mei 2013 Universitas Sulawesi Barat di bawah berubah status dari Perguruan Tinggi Swasta (PTS) menjadi Perguruan Tinggi Negeri (PTN) melalui Peraturan Presiden Republik Indonesia Nomor: 36 Tahun 2013 tentang pendirian Sulawesi Barat. Dengan adanya Peraturan Presiden Republik Indonesia Nomor 36 Tahun 2013 tentang Pendirian Sulawesi Barat berarti bahwa Yayasan Pendidikan Indonesia Sulawesi Barat telah mengalihkan pengelolaan dan aset Universitas Sulawesi Barat kepada Menteri Pendidikan dan Kebudayaan sesuai dengan ketentuan peraturan perundang-undangan.

Berdasarkan data yang diperoleh dari Pangkalan Data Universitas Sulawesi Barat pada tahun 20132019. Diperoleh data bahwa jumlah dosen yang ada di Unsulbar sebanyak 340 yang terdiri dari 20 Program Studi dan 8 Fakultas. Dengan jumlah mahasiswa yang mengalami peningkatan drastis pada tahun 2017-2018 sebanyak 5.906 dan pada tahun 2018-2019 sebanyak 7.940 .

Berdasarkan Undang-undang Republik Indonesia No 14 Tahun 2005 Tentang Guru dan Dosen, Pasal 51 Ayat (1) butir b Dosen berhak mendapatkan promosi dan penghargaan sesuai dengan tugas dan prestasi kerja. Dan butir d Dosen berhak memperoleh kesempatan untuk meningkatkan kompetensi, akses sumber belajar, informasi, sarana dan prasarana pembelajaran, serta penelitian dan pengabdian kepada masyarakat.

Untuk menghasilkan tenaga pendidik yang kompeten sejalan dengan visi dan misi kampus tentunya memerlukan berbagai upaya yang terukur dan berkesinambungan. Banyak upaya yang bisa dilakukan agar tujuan tersebut dapat dicapai, salah satunya penilai kinerja dosen untuk mengetahui tingkat kinerja dosen selama satu semester. Evaluasi ini di upayakan agar terciptanya hal-hal positif terhadap kinerja dosen dalam pelaksanaan tugasnya. Tugas utama dosen pada institusi pendidikan tinggi adalah sebagai pelaksana kegiatan Tri Dharma, sehingga yang akan menjadi sasaran evaluasi kinerja dosen meliputi data BKD dan SKP Dosen Unsulbar. Adapun pokok dari BKD dan SKP Dosen Unsulbar adalah sebagai berikut.
1. Pengajaran
2. Penelitian
3. Pengabdian
4. Penunjan
5. Kerjasama
6. Kedisiplinan
7. Integritas

Hal ini relevan dengan penilaian kinerja dosen setiap intansi Perguruan Tinggi salah satunya Universitas Sulawesi Barat dimana prosesnya terbagi menjadi 2 tahapan :

\section{Penilaian SKP (Sasaran Kerja Pegawai) \\ 2. Penilaian BKD (Beban Kerja Dosen)}

Proses penilaian kinerja Dosen Unsulbar meliputi proses sebagai berikut :

1. Di awal tahun (Januari) dosen membuat SKP (Sasaran Kerja Pegawai) yang akan dilakukan selama 1 tahun (kegiatan Tridarma).

2. Di akhir tahun dosen melaporkan kegiatannya selama 1 tahun

3. Dosen juga membuat review laporan BKD setiap semester (ganjil/genap).

Penilaian Kinerja Dosen penting dilakukan oleh setiap Perguruan Tinggi sebab dengan melakukan penilaian kinerja, Perguruan tinggi dapat dengan mudah melihat potensi dan kinerja dosen. Salah satu manfaat yang dapat diperoleh dari proses penilaian kinerja adalah dapat dengan mudah mengetahui dosen yang memiliki kinerja baik atau bisa disebut dosen teladan. Akan tetapi

proses pemilihan dosen teladan mengalami banyak kesulitan dikarenakan banyaknya jumlah dosen yang dinilai dan membutuhkan proses yang cukup lama.

Berdasarkan pada penelitian sebelumnya Hery Nurmawan, dkk Tahun 2019, melakukan penelitian yang berjudul "Sistem Pendukung Keputusan Karyawan Berprestasi pada Pt. ABC dengan Metode SAW" dengan penilaian kinerja dengan bobot dan kriteria yang telah ditentukan maka akan diketahui prestasi setiap karyawan yang terdiri dari divisi software, development, dan internet service provider, divisi marketing dan divisi infrastruktur. Dengan hasil adalah sebuah sistem pendukung keputusan yang dapat menampilkan daftar karyawan terbaik setiap divisi. Untuk divisi marketing mempunyai Karyawan terbaik dengan nilai tertinggi yaitu 14 poin.

Dengan itu dibutuhkan suatu Sistem Pendukung Keputusan (SPK) dimana SPK adalah suatu sistem yang mampu menyediakan fungsi pengelolaan data berdasarkan suatu model tertentu, sehinga user dari sistem tersebut dapat memilih alternatif keputusan yang terbaik. dengan menggunakan metode Simple Additive Weighting dimana konsep yang digunakan adalah penjumlahan terbobot darirating kinerja dari setiap alternatif pada semua atribut. Dengan proses normalisasi matriks keputusan (X) dalam suatu skala yang diperbandingkan pada rating alternatif yang ada.

\section{Metode Penelitian}

Jenis penelitian yang akan digunakan adalah penelitian data kuantitatif (berbasis perhitungan angka dan statistika) dan kualitatif berdasarkan data 
deskriptif guna memahami suatu fenomena secara mendalam dengan menggunakan landasan teori sebagai panduan untuk memfokuskan penelitian.

Adapun metode yang digunakan dalam menentukan kinerja Dosen Teladan yaitu metode waterfall dengan implementasi algoritma SAW (Simple Additive Weighting).

\subsection{Metode Waterfall}

Metode waterfall merupakan salah satu metode dalam Sistem Development Life Cycle yang digunakan untuk pengembangan suatu perangat lunak. Adapun tahapan dari metode waterfall adalah sebagai berikut.

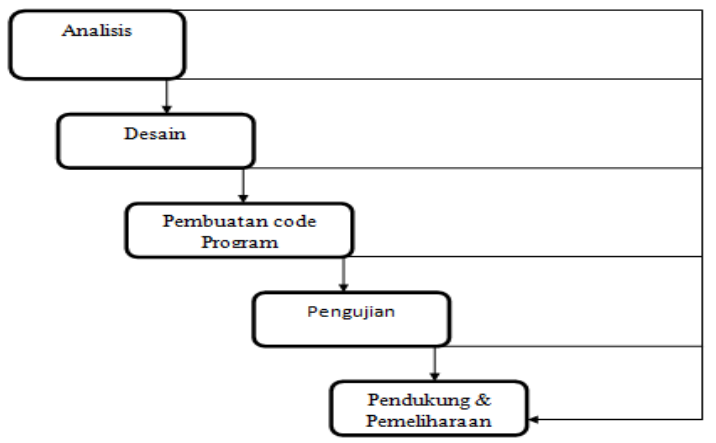

Gambar 1. Tahapan Metode Waterfall

Gambar 1 merupakan tahapan metode waterfall yang secara rinci dijelaskan sebagai berikut.

a. Analisis (Requiretment)

Analisis pengumpulan kebutuhan dilakukan secara intensif untuk menspesifikasikan kebutuhan perangkat lunak agar dapat di pahami perangkat lunak seperti apa yang di butuhkan oleh user baik berupa dokumen, maupun sumber yang lain yang dapat menunjang proses penelitian dalam menentukan solusi permasalahan yang ada. Adapun tahapan analisis yang dilakukan yaitu proses terjung langsung ke lapangan untuk melihat permasalahan yang ada. Dengan melalui proses wawancara, pengumpulan data, dan literatur- literatur jurnal yang terkait dengan penelitian.

b. Desain (Design)

Desain perangkat lunak termasuk struktur data, arsitektur perangkat lunak, representasiantarmuka, dan prosedur pengodean. Tahap ini mentranslasi kebutuhan perangkat lunak dari tahap analisis kebutuhan ke representasi desain agar dapat di implementasikan menjadi program pada tahap selanjutnya. Dalam hal ini dibuat rancangan penentuan dosen teladan berdasarkan penilaian kinerja menggunakan metode simple additive weighting (studi kasus dosen unsulbar) dengan tujuan agar mengetahui bagaimana hasil Implementasi Algoritma Simple
Additive Weighting dalam menentukan penilaian kinerja dosen teladan.

c. Pembuatan Code Program (Implementation) Desain harus di translasikan ke dalam program perangkat lunak. Hasil dari tahap ini adalah program komputer yang sesuai desain yang telah dibuat. Adapun pembuatan sistem program menggunakan PHP Mysql dan Xampp sebagai penghubung database server.

d. Pengujian (Verification)

Pengujian fokus terhadap perangkat lunak (software) secara logic dan fungsional untuk memastikan bahwa semua bagian sudah diuji untuk meminimalisir error (kesalahan) dan keluaran harus sesuai pemilihan cara pengujian dilakukan dengan menggunakan data-data yang sering digunakan untuk pengolahan data, mulai dari data operasional, data input dan output. Adapun teknik pengujian yang digunakan adalah BlackBox Testing untuk melihat tampilan dari hasil program dengan harapan program sudah berjalan sesuai dengan yang diinginkan.

e. Pendukung (Support) atau Pemeliharaan (maintance).

Perubahan dapat terjadi karena adanya kesalahan yang muncul dan tidak terdeteksi saat pengujian atau perangkat lunak harus beradaptasi dengan lingkungan baru. Tahap pendukung atau pemeliharaan dapat mengulangi proses pengembangan mulai dari analisis spesifikasi untuk perubahan perangkat lunak yang sudah ada. Tapi tidak untuk membuat perangkat lunak baru. Dalam hal ini baik perangkat pendukung dan pemeliharaan untuk software maupun hadrware agar dapat diperhatikan dan di update sesuai kebutuhan antara user dan programmer sehingga dapat berjalan sesuai dengan keinginan.

\subsection{Metode Simple Additive Weighting (SAW)}

Menurut Anggraeni dan Oktafianto (2017), Metode Simple Addtive Weighting (SAW) sering juga dikenal dengan istilah metode penjumlahan terbobot. Konsep dasar metode SAW adalah mencari penjumlahan terbobot dari rating kinerja pada setiap alternatif pada semua atribut. Metode SAW membutuhkan proses normalisasi matriks keputusan (X) ke suatu skala yang dapat diperbandingkan dengan semua rating alternatif yang ada.

Menurut Putra dkk (2018), berikut adalah Rumus metode SAW :

$r_{i j}= \begin{cases}\frac{x_{i j}}{\operatorname{Max}_{i} x_{i j}} & \text { jika } \mathrm{j}=\text { atribut keuntungan (benefit) } \\ \frac{\operatorname{Min}_{i} x_{i j}}{x_{i j}} & \text { jika } \mathrm{j}=\text { atribut biaya (cost) }\end{cases}$

Keterangan:

rij $=$ Nilai rating kinerja ternormalisasi

Max xij = Nilai maksimum dari setiap baris dan kolom 
Min $x i j=$ Nilai minimum dari setiap baris dan kolom

$x i j=$ Nilai atribut yang dimiliki dari setiap kriteria

Benefit $=$ Jika nilai terbesar adalah terbaik

Cost $=$ Jika nilai terkecil adalah terbaik

Dengan rij adalah rating kinerja ternormalisasi dari alternatif Ai pada atribut

$$
\begin{aligned}
\mathrm{Cj} ; \mathrm{i}=1,2 \ldots \mathrm{m} \text { dan } \mathrm{j} & =1,2 \ldots \mathrm{n} \\
\mathrm{Vi} & =\sum_{j=1}^{n} w_{j} r_{i j}
\end{aligned}
$$

Nilai preferensi untuk setiap alternatif (Vi) diberikan pada gambar

\section{Keterangan:}

$\mathrm{Vi}=$ Rangking untuk setiap alternative/nilai alternatif $\mathrm{Wj}=$ Nilai bobot rangking dari setiap kriteria

rij = Nilai rating kinerja ternormalisasi

Nilai Vi yang lebih besar mengindikasikan bahwa alternatif Ai lebih terpilih.

\subsection{Langkah-langkah Penyelesaian SAW}

Menurut Mufizar (2015), Langkah-langkah Penyelesaian metode Konsep dasar metode SAW adalah mencari penjumlahan terbobot dari rating kinerja pada setiap alternatif pada semua atribut.

1. Memberikan nilai bobot preferensi (W) oleh pengambil keputusan untuk masing-masing kriteria yang sudah ditentukan.

$$
W=\left[\begin{array}{lllll}
W_{1} & W_{2} & W_{3} & \ldots & W_{j}
\end{array}\right]
$$

$$
1
$$

2. Melakukan normalisasi matriks keputusan Z dengan cara menghitung nilai rating kinerja ternormalisasi (rij) dari alternatif Ai pada atribut $\mathrm{Cj}$.

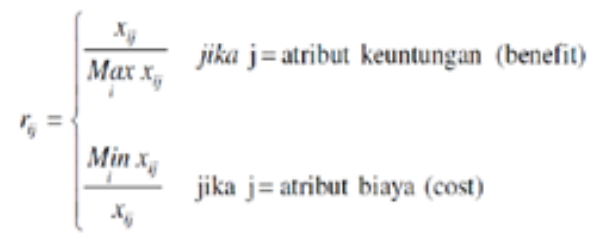

1.

Dengan ketentuan :

a. Dikatakan atribut keuntungan apabila atribut banyak memberikan keuntungan bagi pengambil keputusan, sedangkan atribut biaya merupakan atribut yang banyak memberikan pengeluaran jika nilainya semakin besar bagi pengambil keputusan.

b. Apabila berupa atribut keuntungan maka nilai (xij) dari setiap kolom atribut dibagi dengan nilai (MAX xij) dari tiap kolom, sedangkan untuk atribut biaya, nilai (MIN xij) dari tiap kolom atribut dibagi dengan nilai (xij) setiap kolom.

3. Hasil dari nilai rating kinerja ternormalisasi (rij) membentuk matriks ternormalisasi $(\mathrm{R})$

$$
R=\left[\begin{array}{ccc}
r_{11} & r_{12} \cdots & r_{i j} \\
\vdots & & \vdots \\
r_{i 1} & r_{i 2} \cdots & r_{i j}
\end{array}\right]
$$

4. Melakukan proses perankingan dengan cara mengalikan matriks ternormalisasi $(\mathrm{N})$ dengan nilai bobot preferensi (W).

5. Perangkingan menjumlahkan hasil kali antara matriks ternormalisasi $(\mathrm{N})$ dengan nilai bobot preferensi (W).

$$
\mathrm{Vi}=\sum_{i=1}^{n} w_{j} r_{i j}
$$

Nilai Vi yang lebih besar mengindikasikan bahwa alternatif Ai lebih terpilih.

\subsection{Teknik Analisis Data}

Data yang digunakan dalam penelitian ini adalah data SKP dan BKD Dosen Universitas Sulawesi Barat yang dikategorikan berdasarkan keriteria Pengajaran, Penelitian, Pengabdian, Penunjang,Kerjasama, Kedisiplinan, dan Integritas. Adapun langkah-langkah pengolahan data dapat dilihat pada gambar 2 berikut. 


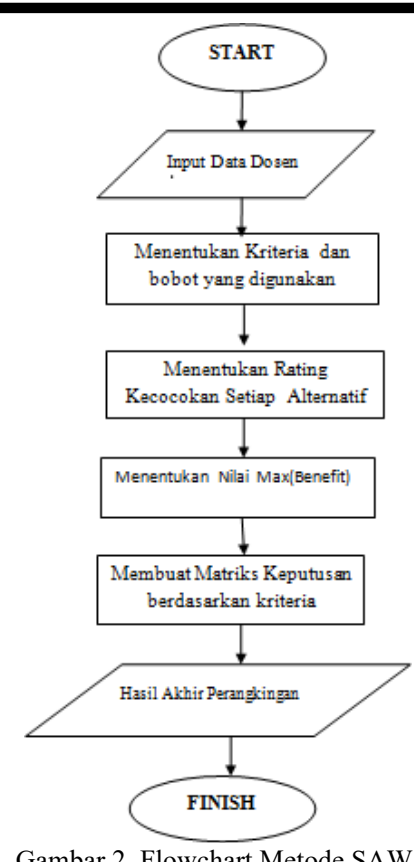

Gambar 2 merupakan langkah - langkah yang akan digunakan dalam metode SAW adalah menentukan bobot kriteria pada penilaian kinerja dosen, selanjutnya menginput data berdasarkan kriteria yang ditentukan, tentukan nilai max, kemudian dilakukan proses normalisasi berdasarkan keputusan matriks (X), didalam proses pelaksanaannya digunakan metode SAW, kemudian kita jumlahkan hasil normalisasi matriks keputusan lalu dikalikan dengan nilai matriks keputusan dengan bobot kriteria preferensi yang telah ditentukan lalu Hasilnya dapat ditarik kesimpulan dengan melihat nilai yang paling tinggi mengindikasikan alternatif Ai yang lebih terpilih dan disebut juga dosen teladan Unsulbar.

\subsection{Teknik Pembobotan Atribut/Kriteria}

Pembobotan kriteria dalam penelitian ini dapat dilihat pada tabel 1 berikut.

Tabel 1. Kriteria/atribut SKP dan BKD

\begin{tabular}{|c|c|}
\hline No & Nama Kriteria/Atribut \\
\hline 1 & Pengajaran \\
\hline 2 & Penelitian \\
\hline 3 & Pengabdian \\
\hline 4 & Penunjang \\
\hline 5 & Kerjasama \\
\hline 6 & Kedisiplinan \\
\hline 7 & Integritas \\
\hline
\end{tabular}

Sumber tabel merujuk pada Data SKP dan BKD pada Dosen Teknik Informatika Universitas Sulawesi Barat.

Adapun pembobotan dari masing-masing kriteria dapat dilihat pada tabel berikut. Pembobotan SKP dapat dilihat pada tabel 2 dan 3 berikut.

\begin{tabular}{|c|c|c|}
\hline Keterangan & $\begin{array}{c}\text { Skala } \\
\text { penilaian }\end{array}$ & Nilai \\
\hline Sangat Baik & $91-100$ & 5 \\
\hline Baik & $76-90$ & 4 \\
\hline Cukup & $66-75$ & 3 \\
\hline Kurang & $51-60$ & 2 \\
\hline Sangat Kurang & $0-50$ & 1 \\
\hline
\end{tabular}

Sumber tabel Merujuk pada penentuan Skala Rating Kecocokan pada journal Mufizar (2015). Serta pada penelitian dengan judul Sistem Pendukung Keputusan Pemilihan Dosen Berprestasi Di STMIK Tasikmalaya Menggunakan Metode Simple Additive Weighting (CSRID Journal, 155- 166).

Tabel 2 merupakan kriteria pembobotan SKP. Berdasarkan data yang ada penulis memberikan poin 5 pada rentang skor penilaian antara 91 - 100 (sangat baik), poin 4 rentang nilai $76-90$ (baik), poin 3 rentang nilai $66-75$ (cukup), poin 2 rentang nilai $51-$ 60 (kurang) dan poin 1 dengan rentang nilai $0-50$ (sangat kurang).

Untuk kriteria penilain BKD dapat dilihat pada tabel 4 dan 5 berikut.

Tabel 4. Penilaian Kriteria BKD

\begin{tabular}{|c|c|}
\hline Keterangan & Nilai \\
\hline Ada & 5 \\
\hline Tidak ada & 1 \\
\hline
\end{tabular}

Sumber tabel merujuk pada Data SKP dan BKD Dosen Teknik Informatika Universitas Sulawesi Barat.

Berdasarkan data yang ada, pada umumnya untuk kriteria BKD penulis memberikan poin 5 jika ada (memenuhi kriteria) dan poin 1 jika tidak ada (tidak memenuhi kriteria), sebagaimana dapat dilihat pada tabel 5 berikut.

Tabel 5. Penilaian BKD Khusus

\begin{tabular}{|c|c|c|}
\hline Keterangan & Skala Penilaian & Nilai \\
\hline Sangat Baik & $>3$ & 5 \\
\hline Baik & 3 & 4 \\
\hline Cukup & 2 & 3 \\
\hline Kurang & 1 & 2 \\
\hline Sangat Kurang & Tidak ada & 1 \\
\hline
\end{tabular}

Sumber tabel merujuk pada Data SKP dan BKD pada Dosen Teknik Informatika Universitas Sulawesi Barat.

Pada tabel 5 diatas, skala penilaian BKD khusus diberikan poin 5 (sangat baik) jika dilakukan $>3$ kali, poin 4 (baik) jika dilakukan 3 kali, poin 3 (cukup) jika dilakukan 2 kali poin 2 (kurang) jika dilakukan 1 kali dan poin 1 (sangat kurang) jika tidak ada.Adapun penilaiannya secara keseluruhan adalah sebagai berikut.

Tabel 6. Skala Prioritas 


\begin{tabular}{|c|c|c|}
\hline No & Kriteria & Poin \\
\hline & BKD & \\
\hline 1 & Pengajaran & 33,36 \\
\hline 2 & Penelitian & 13,9 \\
\hline 3 & Pengabdian & 13,9 \\
\hline \multirow[t]{2}{*}{4} & Penunjang & 30,58 \\
\hline & SKP & \\
\hline 1 & Kerjasama & \multirow{3}{*}{8,34} \\
\hline 2 & Kedisiplinan & \\
\hline 3 & Integritas & \\
\hline \multicolumn{2}{|c|}{ Total } & $100 \%$ \\
\hline
\end{tabular}

Keterangan Tabel 6 Skala Prioritas:

Pengajaran $=33,36$ hasil kali 2,78 $* 12$

Penelitian $=13,9$ hasil kali 2,78 $* 5$

Pengabdian $=13,9$ hasil kali 2,78 $* 5$

Penunjang $=13,9$ hasil kali 2,78* 11

Kerjasama,kedisiplinan, integritas $=8,34$

hasil kali $2,78 * 3$

Jumlah Prioritas 100\% didapatkan dari hasil jumlah kalkulasi kriteria SKP dan BKD Dosen prodi teknik Informatika. Pembobotan dari masing-masing kriterian dapat dilihat pada tabel berikut.

Tabel 7. Pembobotan Kriteria

\begin{tabular}{|c|c|c|c|}
\hline No & $\begin{array}{c}\text { Nama } \\
\text { Kriteria/At } \\
\text { ribut }\end{array}$ & Bobot & Pembulatan \\
Nilai Bobot
\end{tabular}

Berdasarkan data yang ada pada tabel yang merujuk pada skala prioritas. Didapatkan nilai bobot 2,78 masing-masing kriteria yang di dapat dari hasil bagi $(100: 36)=2,78$ atau jika dibulatkan menjadi 3 . Jadi masing-masing bobot preferensi $=3$.

\section{Hasil dan Pembahasan}

\subsection{Hasil Perhitungan Metode SAW}

Penelitian menggunakan data BKD dan SKP Dosen Universitas Sulawesi Barat tahun 2018 - 2019 semester 6 (Genap), dimana teknik yang akan digunakan sesuai dengan metode SAW (Simple Additive Weighting). Dengan hasil dapat mengetahui siapa preferensi Alternatif(Dosen) yang memilki Nilai tertinggi yang mendapat Predikat Dosen Teladan. Dapat dilihat berdasarkan Data yang dilampirkan pada Tabel data di bawah ini :

\begin{tabular}{|c|c|c|c|}
\hline \multicolumn{4}{|c|}{ Rekap BKD semester 6 Genap 2018-2019 } \\
\hline $\begin{array}{c}\text { NO } \\
\text { KRITERIA }\end{array}$ & $\begin{array}{l}\text { HIMPUNAN KRITERIA } \\
\text { PENGAJARAN }\end{array}$ & & NILAI \\
\hline & & $\mathrm{Ya}$ & $\begin{array}{l}\text { Tidak } \\
\text { Ada }\end{array}$ \\
\hline $\mathrm{C} 1$ & $\begin{array}{ll}\text { Melaksanakan Perkuliahan / Tutorial } \\
\text { dan Membimbing, Menguji, serta } \\
\text { Menyelenggarakan Pendidikan ri } \\
\text { Laboratorium, Praktek Keguruan }\end{array}$ & 5 & 1 \\
\hline $\mathrm{C} 2$ & Membimbing Seminar & 5 & 1 \\
\hline C3 & $\begin{array}{l}\text { Membimbing Kuliah Kerja Nyata, } \\
\text { Praktek Kerja Nyata, Praktek Kerja } \\
\text { Lapangan }\end{array}$ & 5 & 1 \\
\hline $\mathrm{C} 4$ & $\begin{array}{l}\text { Membimbing dan Ikut Membimbing } \\
\text { dalam Menghasilkan Disertasi, Tesis, } \\
\text { Skripsi dan Laporan Akhir Studi }\end{array}$ & 5 & 1 \\
\hline $\mathrm{C} 5$ & $\begin{array}{l}\text { Bertugas Sebagai Penguji Pada Ujian } \\
\text { Akhir }\end{array}$ & 5 & 1 \\
\hline C6 & Membina Kegiatan Mahasiswa & 5 & 1 \\
\hline $\mathrm{C} 7$ & Mengembangkan Program Kuliah & 5 & 1 \\
\hline $\mathrm{C} 8$ & Mengembangkan Bahan Pengajaran & 5 & 1 \\
\hline $\mathrm{C} 9$ & Menyampaikan Orasi Ilmiah & 5 & 1 \\
\hline $\mathrm{C} 10$ & $\begin{array}{l}\text { Membimbing Akademi Dosen yang } \\
\text { Lebih Rendah Jabatannya }\end{array}$ & 5 & 1 \\
\hline $\mathrm{C} 11$ & $\begin{array}{l}\text { Melaksanakan Kegiatan Data Sering } \\
\text { dan Pengcangkokan Akademik Dosen }\end{array}$ & 5 & 1 \\
\hline C12 & $\begin{array}{l}\text { Melakukan Kegiatan Pengembangan } \\
\text { Diri untu Meningkatkan Kompetensi }\end{array}$ & 5 & 1 \\
\hline
\end{tabular}

Pada tabel 8 diatas menjelaskan tentang kriteria Pengajaran pada BKD yang terdiri dari himpunan sub kriteria $\mathrm{C} 1$ - C12. Dan pada kolom nilai diberikan poin 5 apabila kriteria memenuhi dan poin 1 jika tidak memenuhi. 


\begin{tabular}{|c|l|c|c|}
\hline \multicolumn{1}{|c|}{ Tabel 9. Sub Kriteria BKD "Penelitian" } \\
$\begin{array}{c}\text { NO } \\
\text { KRITERIA }\end{array}$ & \multicolumn{1}{|c|}{ KRITERIA PENELITIAN } & \multicolumn{2}{|c|}{ NILAI } \\
\hline C13 & Menghasilkan karya ilmiah & 5 & 1 \\
\hline & & \multicolumn{2}{|c|}{ NILAI } \\
\hline C14 & $\begin{array}{l}\text { Menerjemahkan/Penyaduran } \\
\text { buku Ilmiah }\end{array}$ & 5 & Tidak ada \\
\hline C15 & $\begin{array}{l}\text { Mengedit/menyunting Karya } \\
\text { Ilmiah }\end{array}$ & 5 & 1 \\
\hline C16 & $\begin{array}{l}\text { Membuat rencana dan karya } \\
\text { teknologi yang dipatenkan }\end{array}$ & 5 & 1 \\
\hline C17 & $\begin{array}{l}\text { Membuat rancangan dan karya } \\
\text { teknologi, rancangan dan } \\
\text { karyaseni management }\end{array}$ & 5 & 1 \\
\hline
\end{tabular}

Pada tabel 9 diatas menjelaskan tentang kriteria Penelitian pada BKD yang terdiri dari himpunan sub kriteria C13 - C17. Dan pada kolom nilai diberikan poin 5 apabila kriteria memenuhi dan poin 1 jika tidak memenuhi.

Tabel 10. Sub Kriteria BKD "Pengabdian"

\begin{tabular}{|c|l|c|c|}
\hline NO & KRITERIA & KRITERIA PENGABDIAN & \multicolumn{2}{|c|}{ NILAI } \\
\hline \multirow{2}{*}{ C18 } & $\begin{array}{c}\text { Yenduduki Jabatan Pimpinan } \\
\text { Ada }\end{array}$ & 5 & 1 \\
\hline C19 & $\begin{array}{l}\text { Melaksanakan Pengembangan } \\
\text { hasil pendidikan dan penelitian }\end{array}$ & 5 & 1 \\
\hline C20 & $\begin{array}{l}\text { Memberi latihan/ penyuluhan/ } \\
\text { penataran/ceramah pada } \\
\text { masyarakat }\end{array}$ & 5 & 1 \\
\hline C21 & $\begin{array}{l}\text { Memberi pelayanan kepada } \\
\text { masyarakat atau kegiatan lain } \\
\text { yang menunjang pelaksanaan } \\
\text { tugas umum pemerintah dan } \\
\text { pembangunan. }\end{array}$ & 5 & 1 \\
\hline C22 & $\begin{array}{l}\text { Membuat/Menulis Karya } \\
\text { Penelitian }\end{array}$ & 5 & 1 \\
\hline
\end{tabular}

Pada tabel 10 diatas menjelaskan tentang kriteria Pengabdian pada BKD yang terdiri dari himpunan sub kriteria C18 - C22. Dan pada kolom nilai diberikan poin 5 apabila kriteria memenuhi dan poin 1 jika tidak memenuhi.

Tabel 11. Sub Kriteria BKD "Penunjang"

\begin{tabular}{|c|l|c|c|}
\hline $\begin{array}{c}\text { NO } \\
\text { KRITERIA }\end{array}$ & KRITERIA PENUNJANG & \multicolumn{2}{c|}{ NILAI } \\
\hline & Ya & $\begin{array}{c}\text { Tidak } \\
\text { Ada }\end{array}$ \\
\hline C23 & $\begin{array}{l}\text { Menjadi anggota dalam suatu } \\
\text { panitia/badan pada perguruan } \\
\text { tinggi }\end{array}$ & 5 & 1 \\
\hline C24 & $\begin{array}{l}\text { Menjadi anggota panitia/badan } \\
\text { pada lembaga pemerintah }\end{array}$ & 5 & 1 \\
\hline C25 & $\begin{array}{l}\text { Menjadi anggota organisasi } \\
\text { profesi }\end{array}$ & 5 & 1 \\
\hline
\end{tabular}

\begin{tabular}{|c|l|c|c|}
\hline C26 & $\begin{array}{l}\text { Mewakili perguruan } \\
\text { tinggi/lembaga pemerintah }\end{array}$ & 5 & 1 \\
\hline C27 & $\begin{array}{l}\text { Menjadi anggota delegasi } \\
\text { nasional ke pertemuan } \\
\text { internasional }\end{array}$ & 5 & 1 \\
\hline C28 & $\begin{array}{l}\text { Berperan secara aktif dalam } \\
\text { pertemuan ilmiah }\end{array}$ & 5 & 1 \\
\hline C29 & $\begin{array}{l}\text { Mendapat penghargaan/tanda } \\
\text { jasa }\end{array}$ & 5 & 1 \\
\hline C30 & $\begin{array}{l}\text { Menulis buku pelajaran SMTA } \\
\text { ke bawah yang diterbitkan dan } \\
\text { diedarkan secara nasional }\end{array}$ & 5 & 1 \\
\hline C31 & $\begin{array}{l}\text { Mempunyai prestasi di bidang } \\
\text { olahraga/humniora }\end{array}$ & 5 & 1 \\
\hline C32 & $\begin{array}{l}\text { Keanggotaan dalam organisasi } \\
\text { profesi Dosen }\end{array}$ & 5 & 1 \\
\hline C33 & \begin{tabular}{l} 
Keanggotaan dalam Tim Penilai \\
\hline
\end{tabular} & 5 & 1 \\
\hline
\end{tabular}

Pada tabel 11 diatas menjelaskan tentang kriteria Penunjang pada BKD yang terdiri dari himpunan sub kriteria C23 - C33. Dan pada kolom nilai diberikan poin 5 apabila kriteria memenuhi dan poin 1 jika tidak memenuhi.

Tabel 12. Sub Kriteria BKD "Khusus"

\begin{tabular}{|c|c|c|c|}
\hline \begin{tabular}{|c|} 
NO \\
KRITERIA
\end{tabular} & $\begin{array}{l}\text { KRITERIA YANG DILAKUKAN } \\
\text { LEBIH DARI SATU }\end{array}$ & Skala & Nilai \\
\hline $\mathrm{C} 4$ & \begin{tabular}{|lrr} 
Membimbing & dan & Ikut \\
Membimbing & & dalam \\
Menghasilkan & Disertasi, & Tesis, \\
Skripsi dan Laporan Akhir & Studi
\end{tabular} & $\begin{array}{l}> \\
3\end{array}$ & 5 \\
\hline $\mathrm{C} 5$ & $\begin{array}{l}\text { Bertugas Sebagai Penguji Pada } \\
\text { Ujian Akhir }\end{array}$ & 3 & 4 \\
\hline $\mathrm{C} 13$ & Menghasilkan karya ilmiah & 2 & 3 \\
\hline $\mathrm{C} 20$ & $\begin{array}{l}\text { Memberi latihan/ penyuluhan/ } \\
\text { penataran/ceraah pada masyarakat }\end{array}$ & 1 & 2 \\
\hline $\mathrm{C} 32$ & $\begin{array}{l}\text { Keanggotaan dalam organisasi } \\
\text { profesi Dosen }\end{array}$ & $\begin{array}{c}\text { tidak } \\
\text { ada }\end{array}$ & 1 \\
\hline
\end{tabular}

Pada tabel 12 diatas menjelaskan tentang kriteria BKD Khusus yang terdiri dari: penelitian, pengabdian dan penunjang yang dilakukan lebih dari satu kali yang memiliki nilai khusus, yang dapat di perbandingkan. Pada BKD yang terdiri dari himpunan sub kriteria $C 4$, C5, C13. Dan seterusnya. Dan pada kolom nilai diberikan poin 5 apabila penelitian dilakukan $>$ dari 3 kali, poin 4 apabila dilakukan sebanyak 3 kali, poin 3 apabila dilakukan sebanyak 2 kali, poin 2 apabila dilakukan hanya 1 kali. Dan poin 1 apabila tidak ada.

Tabel 13. Sub Kriteria SKP

\begin{tabular}{|c|l|c|c|}
\hline $\begin{array}{c}\text { NO } \\
\text { KRITERIA }\end{array}$ & \multicolumn{1}{|c|}{ KRITERIA SKP } & \multicolumn{2}{c|}{ NILAI } \\
\hline & & Ya & Tidak Ada \\
\hline C34 & Kriteria Kerjasama & 5 & 1 \\
\hline & & & 1 \\
\hline C35 & Kriteria Kedisiplinan & 5 & 1 \\
\hline & & & \\
\hline C36 & Kriteria Integritas & 5 & \\
\hline
\end{tabular}


Pada tabel 13 diatas menjelaskan tentang kriteria Kerjasama, Kedisiplinan, dan Integritas pada SKP yang terdiri dari himpunan sub kriteria C34, C35, C36. Dan pada kolom nilai diberikan poin apabila kriteria tersebut memiliki rentang nilai antara: $91-100$ poin 5 (sangat baik), dengan nilai antara $76-90$ poin 4 (baik),dengan nilai antara $66-75$ poin 3 (cukup), dengan nilai $51-60$ poin 2 (kurang),jika nilai $0-50$ poin 1 (sangat kurang).

Adapun Langkah-langkah penyelesaiannya secara detail dapat dilihat pada lampiran. Hasil dari perhitungan metode SAW dapat dilihat pada gambar 2 berikut.

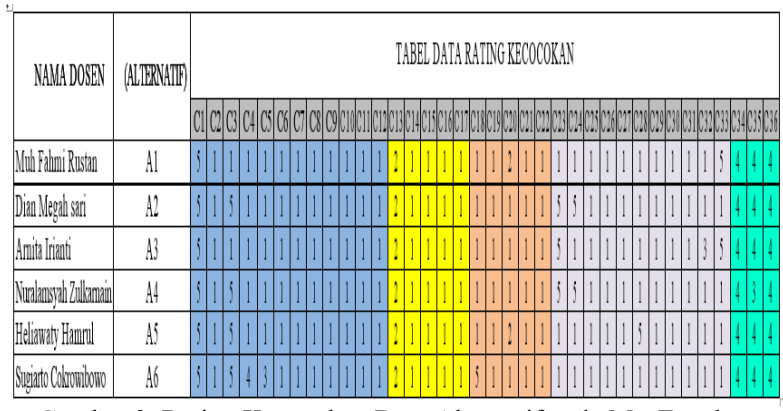

Gambar 3. Rating Kecocokan Data Alternatif pada Ms. Excel

Gambar 3 diatas di dapat dari hasil pencocokan dari masing-masing kriteria BKD dan SKP Tahun 2018-2019 Genap berdasarkan nilai yang dapat di perbandingkan. Dosen Unsulbar Program Studi Teknik Informatika. Setelah di dapat rating kecocokan langkah selanjutnya adalah menentukan sifat dari masing-masing kriteria apakah bernilai benefit atau cost.

a. Dikatakan bernilai benefit apabila atribut banyak memberikan keuntungan bagi pengambil keputusan, sedangkan atribut biaya merupakan atribut yang banyak memberikan pengeluaran (biaya) bagi pengambil keputusan.

b. Apabila berupa atribut keuntungan maka nilai $\mathrm{Rii}=$ (Xij / Max $\{$ Xij $\}$ ) dari tiap kolom, sedangkan untuk atribut biaya, nilai $\mathrm{Rii}=(\mathrm{Xij} / \mathrm{Min}\{\mathrm{Xij}\})$ dari tiap kolom atribut di bagi dengan nilai (Xij) setiap kolom. Maka di dapat hasil Max pada tabel 4.8

Sehingga hasil akhirnya dapat dilihat pada tabel 14 berikut.

Tabel 14. Nilai Preferensi Hasil dari Perhitungan Menggunakan microsoft excel

\begin{tabular}{|c|l|c|}
\hline No & Nama Dosen & Hasil \\
\hline 1 & Muh Fahmi Rustan & 89,75 \\
\hline 2 & Dian Megah Sari & 93,05 \\
\hline 2 & Arnita Irianti & 92,65 \\
\hline 4 & Nuramlamsyah Zulkarnain & 92,30 \\
\hline 5 & Heliawaty Hamrul & 92,15 \\
\hline
\end{tabular}

\begin{tabular}{|l|l|c|}
\hline 6 & Sugiarto Cokrowibowo & 94,90 \\
\hline
\end{tabular}

Tabel 14 merupakan hasil dari perhitungan yang dilakukan menggunakan Microsoft Excel dimana hasil normalisasi matriks keputusan $\mathrm{R}$ nilai rij dikali dengan bobot preferensi (W) yang telah telah ditentukan. Dapat dilihat nilai yang lebih tinggi terdapat pada Dosen Sugiarto Cokrowibowo dengan Nilai 94,90.

\subsection{Antar Muka Program}

Hasil analisa metode SAW kemudian di impelementasikan kedalam aplikasi berbasis website sehingga memudahkan user untuk melakukan perhitungan Kinerja Dosen Teladan. Adapun tampilan user interfacenya dapat dilihat pada gambar 3-8 berikut.

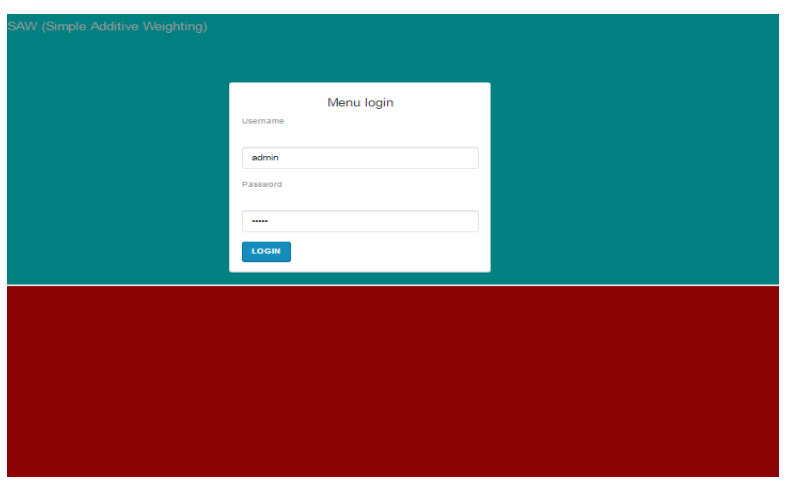

Gambar 4. Tampilan Login

Gambar 4 merupakan tampilan login dimana admin memasukkan username dan password. Untuk menampilkan halaman menu yang tersedia pada program seperti: Saw, Home, Nilai, kriteria, Alternatif, Rangking, dan Laporan sehingga dapat di akses oleh user.

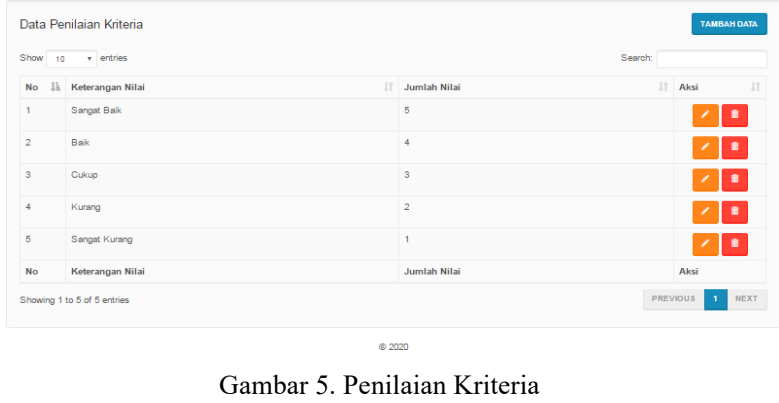

Gambar 5 menunjukkan Data Nilai Preferensi untuk menampilkan nilai yang dijadikan kategori penilaian seperti sangat baik, baik, cukup, kurang, dan sangat kurang. Data diperoleh berdasarkan skala perbandingan yang dibuat dengan melihat Data Yang ada pada penelitian yaitu BKD dan SKP Dosen Unsulbar Prodi Teknik Informatika. 


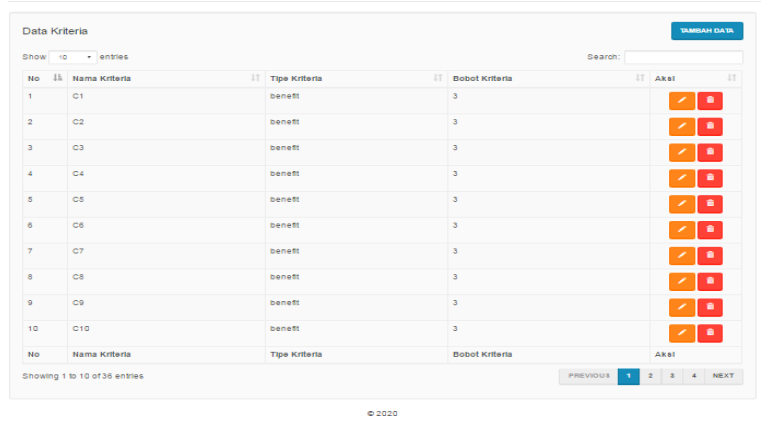

Gambar 6. Data Kriteria: Input Kriteria, Tipe dan Bobot Kriteria.

Gambar 6 menampilkan Data Kriteria yang terdiri dari Nama Kriteria, Tipe Kriteria, dan Bobot Kriteria. Pada kolom nama kriteria tersebut C1- C36 di dapat dari sub kriteria yang digunakan pada Data SKP dan BKD dosen yang terdiri dari: pengajaran, Penelitian, Pengabdian, Penunjang, Kerjasama, Kedisiplinan, Integritas, pada tipe kriteria menggunakan sifat benefit dimana kriteria memiliki komponen penting atau bermanfaat pada Dosen yang termasuk pada Tridarma Dosen. Pada bobot kriteria ditentukanberdasarkan data BKD dan SKP dosen Unsulbar Prodi Teknik Informatika.

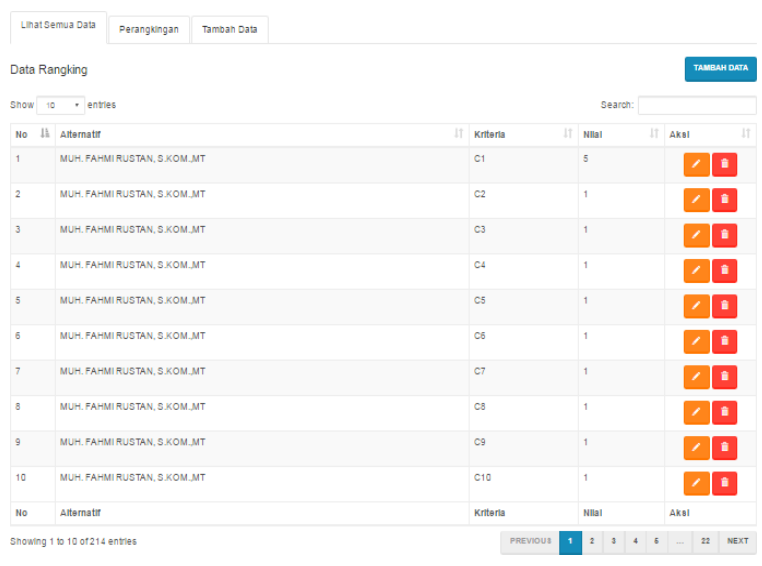

Gambar 7. Data Perangkingan.

Gambar 7 menampilkan Alternatif, Kriteria, dan Nilai Dimana alternatif di dapatkan dari objek penelitian atau Dosen Prodi Teknik Informatika, Kriteria yang didapatkan dari sumber data BKD dan SKP tahun 2019 yang digunakan di prodi teknik informatika, dan Nilai di dapatkan dari hasil BKD dan SKP yang telah akumulasikan sesuai rentang skala penilaian yang digunakan.

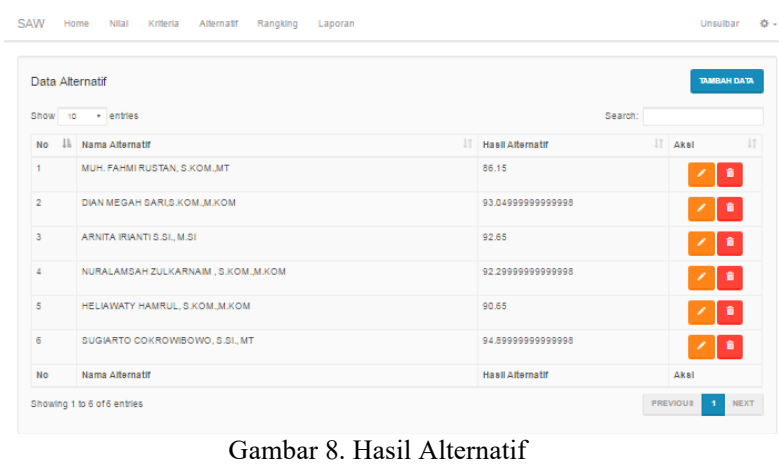

Gambar 8 Hasil Alternatif menampilkan Nama Alternatif (Dosen) dan jumlah Akumulasi data BKD dan SKP pada tiap-tiap masing Dosen Unsulbar Prodi Tenik Informatika.

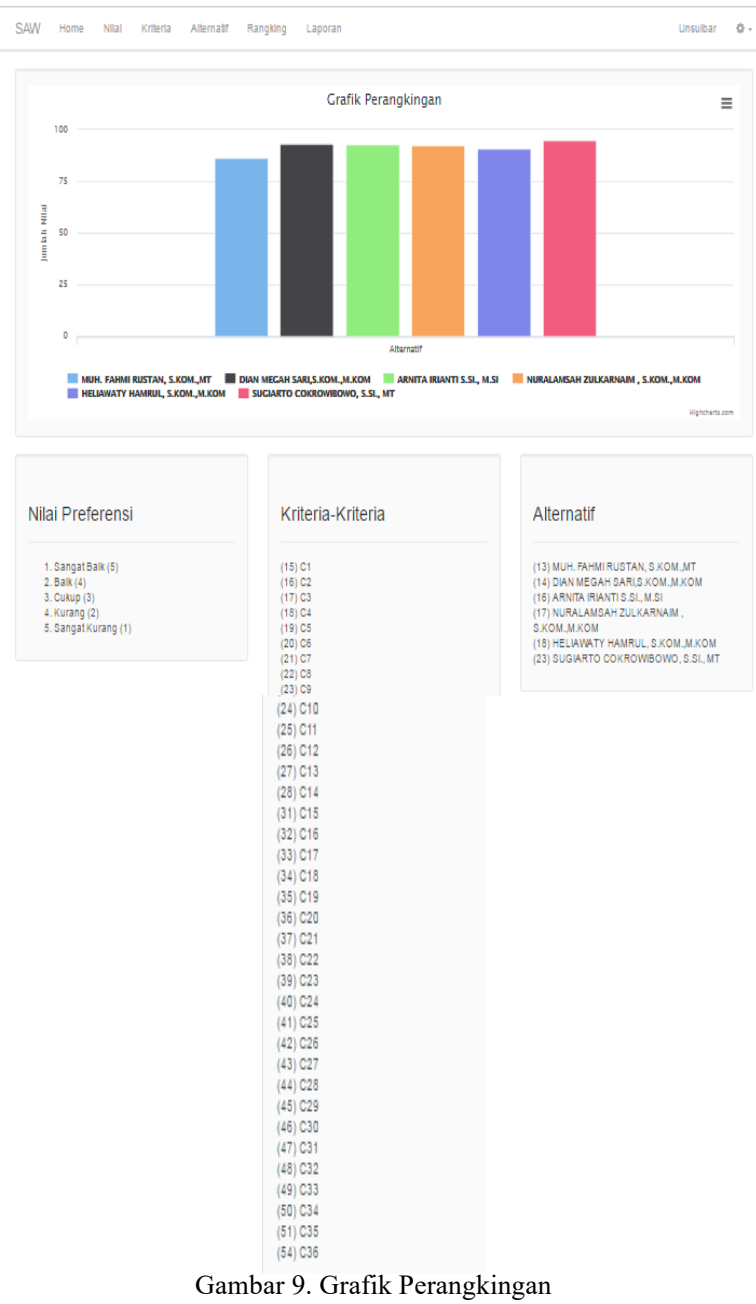

Gambar 9 menampilakan Grafik Perangkingan berdasarkan hasil alternatif yang dapat dibedakan berdasarkan Warna, Nilai dan Nama dosen dimana pada grafik tersebut menunjukkan hasil persentase berdasarkan data SKP dan BKD Dosen Unsulbar Prodi Teknik Informatika.

\subsection{Black Box Testing.}

Pengujian Blackbox

Menurut Jaya Snadika Tri (2018), Black-Box Testing merupakan Teknik pengujian perangkat lunak yang berfokus pada spesifikasi fungsional dari perangkat lunak.Blackbox Testing bekerja dengan mengabaikan struktur kontrol sehingga perhatiannya difokuskan pada informasi domain. 

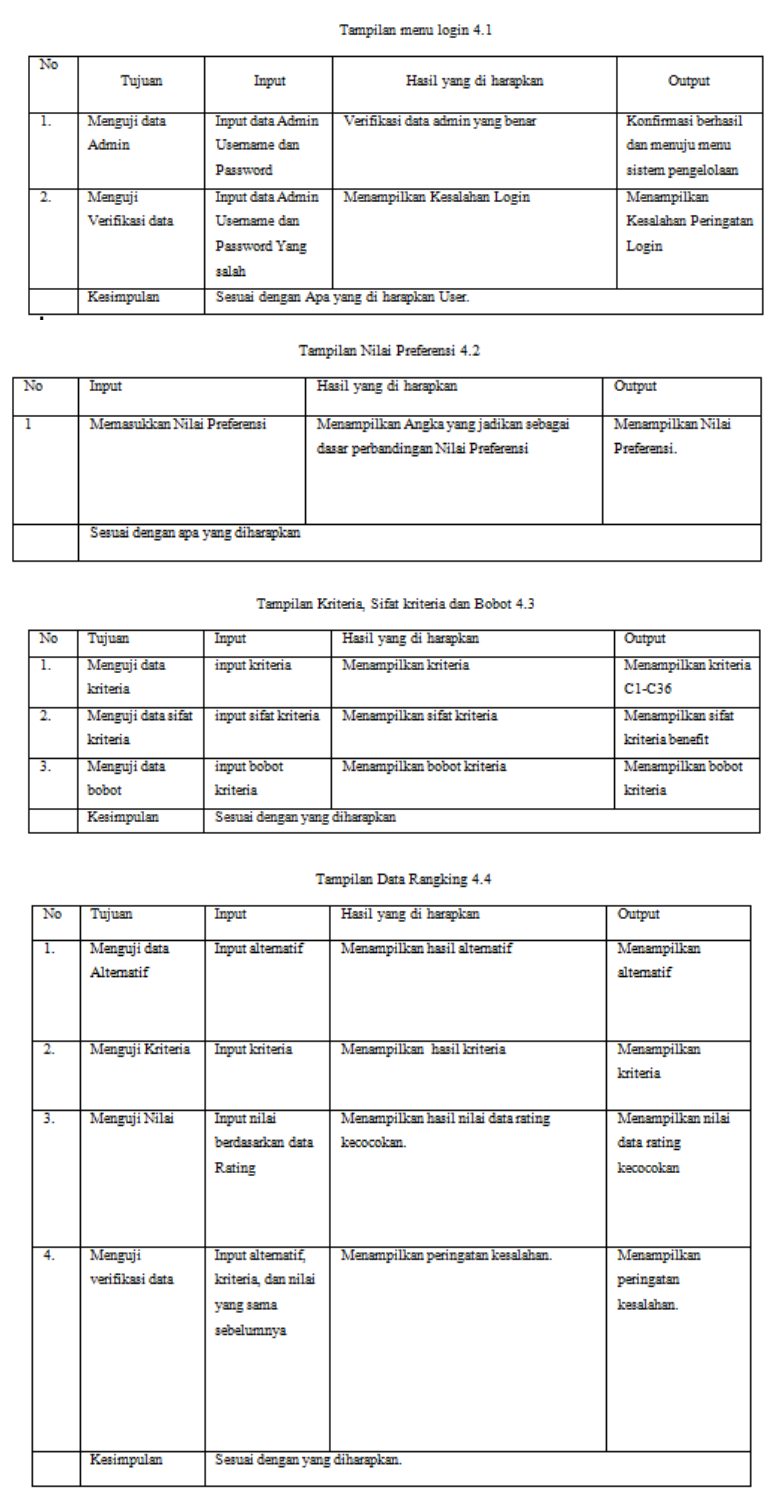

Tampilan Hasil Altematif 4.5

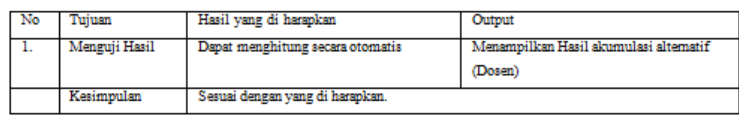

Tampilan Grafik Perangkingan 4.6

\begin{tabular}{|c|c|c|c|}
\hline No & Tujuan & Hasil yang di harapklan & Output \\
\hline \begin{tabular}{|l}
1. \\
.
\end{tabular} & Menguji data & $\begin{array}{l}\text { Dapst mensampilkan grafik } \\
\text { perangkingan dosen teladan } \\
\text { berdasarkan data yang ada }\end{array}$ & $\begin{array}{l}\text { Menampillkan Grafik perangkingan dosen teladan } \\
\text { dapat dilihat dari grafilyang lebih tinggi adalah } \\
\text { dosen yang lebih teppilih }\end{array}$ \\
\hline & Kesimpulen & nyang diharapk: & \\
\hline
\end{tabular}

\section{Kesimpulan}

Berdasarkan penelitian yang sudah dilakukan dengan merujuk pada data yang ada, dan referensireferensi yang telah menambah ilmu pengetahuan yang baru maka, penulis dapat menarik kesimpulan dari penelitian mengenai: Penentuan Dosen Teladan Berdasarkan Penilaian Kinerja Menggunakan Metode Simple Additive Weighting (Studi Kasus Dosen Unsulbar) dapat di implementasikan dengan melihat rujukan pada perhitungan manual dan program dimana data yang dihasilkan sama nilai tertinggi tetap dimiliki oleh A6 (Sugiarto Cokrowibowo) dimana dapat dibuktikan dalam perhitungan excel A6 diperoleh nilai 94,90 perhintungan secara manual nilai 94,89 dan Program nilai 94,89 . Dimana dosen yang memilki predikat nilai yang lebih tinggi atau disebut juga dosen teladan uiversitas sulawesi barat prodi teknik informatika jatuh kepada Dosen Sugiarto Cokrowibowo.

\section{Ucapan Terimakasih}

Terima kasih yang tak terhingga penulis ucapkan kepada Bapak dan Ibu Dosen serta pihak akademik Universitas Sulawesi Barat yang telah banyak membantu proses penelitian ini. Tidak lupa terima kasih kepada Tim Reviewer dan Penerbit.

\section{Daftar Rujukan}

[1] Asnawi, M.F.. dan Muwafiq B.M.A.,2019, Implementasi Metode Simple Addtive Weight (SAW) pada Sistem Pendukung keputusan Penentuan Dosen Berprestasi,Vol.6No.3.

[2] Erdawati., Linarta, A., Ardianto, S., dan Yunita, P., 2016, Sistem Pendukung Keputusan Pemilihan Dosen Berprestasi Menggunakan Metode Analytical HierarcyProcess(AHP), Vol.8No.2.

[3] Kuntilatifah,S., dan Irawan, D., 2017, Sistem Pendukung Keputusan Guru Berprestasi di SD Negeri 04 Watuagung Menggunakan Metode SAW,Vol.5No.1.

[4] Mufizar, T., 2015, Sistem Pendukung Keputusan Pemilihan Dosen Berprestasi di STMIK Tasikmalaya Menggunakan Metode Simple Additive Weighting (SAW),Vol.7No.3.

[5] Nurmawan, H., Andriani,Y.F., dan Kusrini, 2019, Sistem Pendukung Keputusan Karyawan Berprestasi Pada Pt. Abc Dengan Metode Saw, Vol.5 No.1.

[6] Nurlaela, S., Akmaluddin., Hadianti S., dan Yusuf L, 2019, Penyeleksian Jurusan Terfavorit Pada SMK Sirajul Falah dengan Metode SAW, Vol.15 No. 1.

[7] Saputra, R.H., Baba, J.A., dan Siregar,G.Y.K.S., 2018, Penilaian Kinerja Dosen Menggunakan Modifikasi Skala Likert Dengan Metode Simple AdditiveWeighting,Vol.9No.1. 